Article

\title{
Cristianismo y pandemia en Argentina. Notas sobre la secularización del discurso religioso
}

\author{
Diego MAURO' ${ }^{1}$, MARIANO FABRIS ${ }^{2}$
}

\begin{abstract}
Resumen. El presente ensayo se pregunta por el lugar que los especialistas religiosos le otorgan a la religión en el contexto particular creado por la pandemia. A lo largo del artículo nos acercamos a algunas respuestas posibles y provisorias analizando lo que ocurrió en Argentina con los principales referentes católicos y evangélicos. Sostenemos a modo de hipótesis que el discurso de estos actores religiosos sobre la pandemia tuvo un bajo nivel de encantamiento y se basó en una mirada mayormente secularizada de la sociedad, la salud y la vida política, desprovista, además, de tintes apocalípticos y conspiracionistas. Por otro lado, afirmamos que, si bien las instituciones religiosas cristianas apoyaron desde el comienzo las medidas sanitarias del gobierno, con el paso de los meses, fueron surgiendo voces críticas que confluyeron en el reclamo de un mayor reconocimiento de lo religioso en las políticas públicas.
\end{abstract}

Palabras claves: Iglesia católica, evangélicos, pandemia, Argentina.

\begin{abstract}
The article analyzes the discourse of religious specialists on the pandemic. Throughout the essay we offer some provisional answers based on what happened in Argentina with the authorities of the Catholic Church and the associations of evangelical churches. We defend the hypothesis that the discourse of these religious actors about the pandemic had a low level of enchantment. We also affirm that it was based on a secularized view of society, health and politics, devoid of apocalyptic and conspiratorial perspectives. On the other hand, we affirm that two moments can be demarcated. In the first months, Christian religious institutions supported the government's health measures. However, in the following months, critical voices emerged demanding more attention to religion in public policy.
\end{abstract}

Keywords: Catholic Church, Evangelicals, Pandemic, Argentina.

\section{Introducción}

Las preocupaciones que motivan el presente ensayo podrían sintetizarse en una pregunta amplia: ¿Cuál es el lugar que los especialistas religiosos le otorgan a la religión en el contexto particular creado por la pandemia del Covid19? Nuestra respuesta será más aco-

\footnotetext{
${ }^{1}$ Investigaciones Socio-históricas Regionales (ISHIR), Universidad Nacional de Rosario. Consejo Nacional de Investigaciones Científicas y Técnicas (CONICET), Argentina. Email: diegomauro@conicet.gov.ar

${ }^{2}$ Instituto de Humanidades y Ciencias Sociales (INHUS). Universidad Nacional de Mar del Plata. Consejo Nacional de Investigaciones Científicas y Técnicas (CONICET), Argentina. Email: marianofabris76@gmail.com
}

Copyright $\odot 2021$ The Author(s). Open Access. This in an open access article published by Firenze University Press (www.fupress.net/index.php/ccselap) and distributed under the terms of the Creative Commons Attribution 4.0 International License. The Creative Commons Public Domain Dedication waiver applies to the data made available in this article, unless otherwise stated. 
tada, ya que nos enfocaremos en el caso argentino y, en particular, en obispos católicos y referentes evangélicos. Pero, además, será necesariamente provisoria en la medida en que trataremos de ofrecer una lectura del proceso mientras sigue su propia dinámica. ${ }^{3}$

A comienzos de septiembre del 2020, circuló una fakenews que tuvo bastante repercusión, al menos en círculos intelectuales o académicos que, tal vez por "defectos de formación", la hallaron perfectamente lógica. Se trató de un supuesto comunicado del Arzobispado de Salta, en el norte argentino, en el que se aclaraba que se suspendía la habitual procesión de la Virgen del Milagro "habida cuenta que su capacidad de protección" estaba "destinada solo a terremotos y no a pandemias". El falso comunicado generó inmediatamente una catarata de memes en las redes sociales y reavivó algunas de las tónicas tradicionales del discurso anticlerical centradas en la supuesta incompatibilidad entre ciencia, saber biomédico, espiritualidad y religión. La amplia circulación de dicha fakenews dirigida a ridiculizar las creencias religiosas se debió, en cierta medida, al hecho de que el Arzobispado de Salta esperó hasta último momento para suspender la tradicional procesión -que, por otro lado, ya habían iniciado muchos peregrinos desde otros punto de la provincia-, pero, fundamentalmente, a la propia estructura del discurso anticlerical, afirmado especularmente en una fe de dogmas también inconmovibles y en una concepción de lo religioso fuertemente marcada por los presupuestos de la ilustración (Di Stefano y Zanca, 2013). También por la experiencia histórica precedente ya que los obispos argentinos tienen en su haber un largo listado de pedidos de intervención (intercesión) a la virgen para frenar catástrofes de todo tipo -desde terremotos e inundaciones a epidemias- y hasta el avance de ideologías consideradas amenazantes -particularmente el laicismo, el anarquismo o el comunismo- (Di Stefano y Zanatta, 2000; Ghio, 2007; Lida, 2015). No obstante, a lo largo de estos meses, la Iglesia católica ha buscado armonizar y complementar las posturas derivadas del saber biomédico con una concepción integral pero diferenciada de lo humano, que coloca a lo religioso en serie con otros aspectos más que como un principio jerárquico de orden. Lo mismo puede decirse de las principales asociaciones de iglesias evangélicas de Argentina, tales los casos de la Alianza Cristiana de Iglesias Evangélicas de la República Argentina (ACIERA) y de la Federación Argentina de Iglesias Evangélicas (FAIE). En sus comunicados oficiales, desde el inicio de la pandemia, asumieron una postura de colaboración activa con las medidas de aislamiento y, de ese modo, contribuyeron significativamente a afirmar la autoridad del saber biomédico -y del Estado- en amplios sectores de la población. El éxito inicial de las medidas tomadas por el gobierno, de hecho, no puede desconectarse del fuerte apoyo que recibió de las instituciones religiosas.

Con el transcurso de los meses, sin embargo, aparecieron matices e incluso un cierto malestar. Por un lado, fueron surgiendo algunos discursos críticos centrados en el lugar que el comité de expertos que asesora al gobierno le daba a lo religioso. Por otro, el resurgimiento de los enfrentamientos entre el gobierno y sectores de la oposición política, tras el breve período de confluencia al inicio del Aislamiento Social, Preventivo y Obligatorio (ASPO), comenzó a permear también el discurso de los actores religiosos.

\footnotetext{
${ }^{3}$ El Blog de Diversa, la Red de Estudios de la Diversidad Religiosa en la Argentina, compiló una serie de trabajos en curso sobre religiones y pandemia que ofrecen un buen estado de la cuestión sobre las investigaciones actuales en Argentina y América Latina. Recuperado en: http://www.diversidadreligiosa.com.ar/blog/tag/covid-19

4 "La Virgen del milagro de Salta no cubre pandemias", 14/09/2020. Recuperado de: https://www.elextremosur. com/nota/26332
} 
Partiendo de estas consideraciones, sostenemos dos hipótesis cuyo carácter aparentemente paradojal da cuenta de la dinámica propia de un proceso en constante redefinición. Entendemos, por un lado, que el discurso de obispos católicos y referentes evangélicos sobre la pandemia tuvo un bajo nivel de encantamiento y se basó en una mirada mayormente secularizada de la sociedad, la salud y la vida política, desprovista, además, de tintes apocalípticos y conspiracionistas (Frigerio, 2020). La ausencia de estas dos últimas dimensiones limitó considerablemente la confluencia de las críticas provenientes de las instituciones religiosas con la de los denominados grupos "anticuarentena". ${ }^{5}$ Por otro lado, consideramos que, sin dejar necesariamente de apoyar el ASPO, también se desplegó un discurso en el que se relanzaba una crítica a la modernidad liberal y a las ideas de autosuficiencia y autodeterminación asociadas a dicho horizonte. Desde esta postura, que como veremos no dejaba de entrever una concepción diferenciada de lo religioso y de lo espiritual respecto de otras dimensiones de la vida social y política, se entendía que la pandemia había expuesto las debilidades humanas y había generado las condiciones para una relocalización de la dimensión espiritual. El planteo no suponía una impugnación de los fundamentos del saber biomédico ni de las políticas estatales, aunque implicaba el reclamo por un mayor reconocimiento de lo religioso en las políticas del gobierno. En ocasiones, se escucharon también críticas más duras que, provenientes sobre todo de sectores de la oposición política, llegaron a hablar de falta de "libertad religiosa" y de un "Estado omnipotente" y "autoritario". Dichas expresiones, sin embargo, encontraron muy poco eco en las principales autoridades de la Iglesia católica y del mundo evangélico, como veremos, mucho más cautas y proclives al diálogo.

El artículo está organizado en dos apartados que pretenden captar estos discursos que, si bien se suceden temporalmente entre marzo y finales de agosto, también se entrecruzan en diferentes momentos. En un primer apartado, entonces, ponemos el foco en los posicionamientos tempranos frente al ASPO y la pandemia, mayormente secularizados y con una fuerte presencia del eje sanitario. Posteriormente, avanzamos a través de un camino más sinuoso, donde aparecen matices significativos y diferentes voces al tiempo en que el discurso religioso se va tensionando al calor de la polarización política.

\section{Los discursos religiosos y el respaldo al ASPO}

Ante las primeras medidas tomadas por el gobierno el 14 de marzo, el obispo auxiliar de La Plata y presidente de la Comisión Episcopal para la Pastoral de la Salud, monseñor Alberto Bochatey, señaló que frente a la situación que vivía el mundo, estaba bien "rezarle a Jesús" pero sin por ello dejar de "confiar en la ciencia y en los médicos". ${ }^{6}$ Por su parte, desde ACIERA se recalcó la total predisposición de las iglesias nucleadas en su asociación para colaborar con el gobierno y se pidió al Espíritu Santo la fuerza necesaria para enfrentar la pandemia.

\footnotetext{
${ }^{5}$ Estos grupos, según señala Viotti, tienen en común, precisamente, el "asumir teorías conspirativas sobre agentes externos, planes maquiavélicos y poblaciones engañadas" basadas en el "rechazo de la evidencia oficial" como "marca de identidad" para "presentarse en el espacio público" (Viotti, 2020).

${ }^{6}$ Mons. Bochatey llamó a rezar y confiar en la ciencia (2020, 18 de marzo). Boletín de la Agencia Informativa Católica Argentina (BO-AICA). Recuperado de https://www.aica.org/noticia-mons-bochatey-llamo-a-rezar-y-confiar-en-la-ciencia.
} 
El 20 de marzo, tras el anuncio del ASPO, representantes de la cúpula eclesiástica de la Iglesia católica y de las principales asociaciones de iglesias evangélicas se reunieron con el presidente de la nación, Alberto Fernández, para transmitir su apoyo a las medidas implementadas y ofrecer colaboración tanto espiritual como material. ${ }^{7}$ En varias diócesis los obispos se reunieron con gobernadores e intendentes municipales, ya sea para anunciar medidas que afectaban al culto, como en el caso de Catamarca donde se suspendió el Congreso Mariano, ${ }^{8}$ o para coordinar acciones de asistencia social como fue el caso en algunos municipios del Área Metropolitana de Buenos Aires (AMBA). ${ }^{9}$ En el distrito de Quilmes, uno de los más densamente poblados de la provincia de Buenos Aires, el obispo local, Carlos José Tissera, recibió a la intendenta Mayra Mendoza para una charla en la que, según lo informado, los ejes principales fueron la situación social, el hambre y la pandemia. ${ }^{10}$ En San Miguel, también provincia de Buenos Aires, la municipalidad firmó un convenio con los jesuitas, quienes cedieron parte de las instalaciones del Colegio Máximo en dicha ciudad para la internación de enfermos leves. ${ }^{11}$ A nivel nacional, FAIE puso en marcha un relevamiento para ofrecer ayuda al gobierno y ACIERA planteó algo similar, acompañado de una cadena de oración. ${ }^{12}$

En las semanas iniciales, los principales actores políticos y sociales parecieron dejar de lado sus diferencias y priorizar la búsqueda de compromiso y colaboración en la lucha contra el virus. En esa empresa contaban con el respaldo de los medios de comunicación y de la sociedad, cuyas expresiones de apoyo al personal sanitario constituirían una de las postales más conmovedoras -aunque efímeras- de la pandemia. Con entusiasmo, periodistas y comunicadores comenzaron a especular con la superación de la llamada "grieta", metáfora que da cuenta de la polarización política que arrastra el país desde hace varios años. Los principales referentes religiosos se mostraron en sintonía, valoraron las expresiones de conciliación social y buscaron asumir un rol protagónico, apoyando las medidas sanitarias y socioeconómicas.

El poder político y las iglesias coincidieron en que el escenario se tornaba complicado en las ciudades más populosas y en los barrios humildes del AMBA, ${ }^{13}$ tanto por las situaciones

\footnotetext{
${ }^{7}$ Dinatale, M. (2020, 20 de marzo). La cúpula de la Iglesia se reunió con Alberto Fernández y le transmitió su apoyo ante la crisis generada por el coronavirus. Infobae. Recuperado de https:/www.infobae.com/politica/2020/03/20/la-cupula-de-la-iglesia-se-reunio-con-alberto-fernandez-y-le-transmitio-su-apoyo-ante-la-crisis-generada-por-el-coronavirus/

${ }^{8}$ Mons. Urbanc: "Tenemos que ser cautelosos" (2020, 11 de marzo). BO-AICA. Recuperado de https://aica.org/ noticia-mons-urbanc-tenemos-que-ser-cautelosos.

${ }^{9}$ Sobre esto, aunque no específicamente vinculado al contexto generado por el coronavirus, a principios de marzo se habían firmado acuerdos con la participación del secretario de Culto de la Nación, Guillermo Oliveri, y el ministro de Desarrollo Social, Daniel Arroyo, a través de los cuales se buscaba articular la participación de las organizaciones dependientes de las Iglesias en planes de acción social. Promueven mayor participación de las organizaciones religiosas en la acción social (2020, 12 de marzo). BO-AICA. Recuperado dehttps://www.aica.org/ noticia-promueven-mayor-participacion-de-las-organizaciones-religiosas-en-la-accion-sociall.

${ }^{10}$ Los obispos de Quilmes recibieron a la intendenta Mendoza (2020, 17 de marzo). BO-AICA. Recuperado de https://www.aica.org/noticia-los-obispos-de-quilmes-recibieron-a-la-intendenta-mendoza

${ }^{11}$ Coronavirus: El Colegio Máximo cede instalaciones para atender a los pacientes (2020, 27 de marzo). BO-AI$C A$. Recuperado de https://www.aica.org/noticia-coronavirus-el-colegio-maximo-cede-instalaciones-para-atender-a-los-pacientes.

${ }^{12}$ Uranga, W. (2020, 24 de marzo). Coronavirus: las instituciones religiosas ofrecen lugares para alojar enfermos. Pagina 12. Recuperado de https://www.pagina12.com.ar/254849-coronavirus-las-instituciones-religiosas-ofrecen-lugares-par.

${ }^{13}$ El AMBA es la zona común que conforman la Ciudad Autónoma de Buenos Aires y los cuarenta municipios circundantes, con una población de más de 14 millones de habitantes.
} 
de pobreza que el aislamiento profundizaría, como por el impacto que podría tener el virus en zonas donde predominaba el hacinamiento, la falta de servicios básicos y la debilidad de las estructuras de contención sanitaria. No fue casual entonces que el 25 de marzo el presidente de la nación se reuniera con los responsables de la Pastoral de Villas Miserias encabezados por el obispo auxiliar de la arquidiócesis de Buenos Aires, Gustavo Carrara. ${ }^{14}$ El día anterior, ACIERA había hecho llegar al gobierno el resultado de su relevamiento: 1300 camas en diferentes iglesias, templos y entidades cristianas. En la carta enviada al presidente señalaban: "Queremos que sepa que nuestros templos, lugares de culto, múltiples instalaciones, recursos y voluntariado, están al servicio del país para todo aquello en que se lo necesite". 15

La preocupación por la situación sanitaria y las condiciones socioeconómicas, no invalidó la proliferación de lecturas más generales que comprendían la pandemia en términos de una profunda alteración en la relación del ser humano con la trascendencia. En las intervenciones de algunos especialistas religiosos -empezando nada menos que por el papa Francisco, en el caso de los católicos- ganó predicamento la idea de que se asistía a una crisis de autosuficiencia del ser humano, que, confrontado con la incertidumbre y el temor propio de la pandemia, tomaba conciencia de sus limitaciones y debilidades. Como telón de fondo de la pandemia se manifestaba, en forma trágica, el fracaso de las promesas existenciales de la modernidad. La pandemia despojaba al hombre moderno de la "omnipotencia" que lo había alejado de Dios.

Desde el diario cordobés La Voz el obispo auxiliar de Córdoba, monseñor Torres, aseguró "que una pandemia nos muestra que fronteras humanas defendidas por siglos con tantas armas y guerras fratricidas, han caído por gotas de saliva que dejaron expuesta nuestra fragilidad, hermanándonos en el dolor y la solidaridad para cuidar la vida". ${ }^{16}$ Para el obispo de Avellaneda-Lanús, Rubén Frassia, la pandemia desnudaba el fondo de crisis existencial de la sociedad y obligaba a “ ¡Buscar el sentido! ¡El sentido de persona! ¡El sentido de hijos de Dios! ¡El sentido de hermanos con los hermanos! ¡El sentido entre todos!”.17 El arzobispo de Corrientes, monseñor Andrés Stanovnik, afirmó:

Ya no hay ningún lugar en el mundo donde asegurarnos para que nada ni nadie nos moleste; de muy poco sirven los cercos, los muros, las alarmas y otras defensas que podamos inventar. La fragilidad humana en la que nos puso la pandemia nos tiene que llevar a descubrir dónde está la verdadera fortaleza del ser humano y, por ende, de la familia humana. ${ }^{18}$

En Familia Cristiana, revista de extensa trayectoria editada por la asociación Hijas de San Pablo y una de las más leídas por el laicado católico, se señalaba que se había ido

\footnotetext{
${ }^{14}$ Mons. Carrara: "Llevamos al presidente nuestra mirada acerca de la cuarentena en los barrios" (2020, 26 de marzo). BO-AICA. Recuperado de https://www.aica.org/noticia-mons-carrara-llevamos-al-presidente-nuestra-mirada-acerca-de-la-cuarentena-en-los-barrios.

${ }^{15}$ ACIERA pone a disposición camas y edificios de iglesias por pedido del gobierno nacional (2020, 30 de marzo). Recuperado de https://www.aciera.org/aciera-pone-a-disposicion-camas-y-edificios-de-iglesias-por-pedido-del-gobierno-nacional/.

${ }^{16}$ Torres, P. (2020, 24 de marzo). Necesidad de contemplación. La Voz. Recuperado de https://www.lavoz.com.ar/ opinion/necesidad-de-contemplacion.

${ }^{17}$ Mons. Frassia deseó que esta situación "nos ayude a ayudarnos" (2020, 27 de marzo). BO-AICA. Recuperado de https://www.aica.org/noticia-mons-frassia-deseo-que-esta-situacion-nos-ayude-a-ayudarnos.

${ }^{18}$ Mons. Stanovnik: Ninguna fuerza en el universo puede destruir el amor (2020, 6 de abril). BO-AICA. Recuperado de https://aica.org/noticia-mons-stanovnik-ninguna-fuerza-en-el-universo-puede-destruir-el-amor.
} 
reemplazando la "idea de un Dios Omnipotente" por la idea "del Hombre Omnipotente", pero que ahora, ante el avance de la pandemia, "nos damos cuenta que no lo somos y caemos en la desesperación. De repente se nos abrieron los ojos (...) no somos dioses como esta sociedad nos estaba haciendo creer" ${ }^{19}$ En la misma revista y a propósito de la Pascua vivida en este contexto singular se sostenía que el "progreso de la ciencia y de la técnica, los altos niveles de bienestar que disfrutamos en Occidente -al menos, la mayoría de las personas- nos prometen continuamente el paraíso en la tierra y nos dejamos engañar pensando que estamos a un tris de hallar aquí, en esta tierra, la felicidad y la plenitud". ${ }^{20}$

Desde ACIERA se insistió en la misma dirección. En uno de los ciclos de charlas virtuales lanzados señalaban que frente al virus se experimentaba un "grado alto de vulnerabilidad, con un sentimiento de miedo global" que solo la religión podía ayudar a sobrellevar. Por su parte, el Consejo Directivo Nacional de la asociación consideró que "la Biblia" permitía tener una "mirada retrospectiva en la historia. Ante lo cual podemos afirmar que también de esta situación saldremos fortalecidos" y pedían no dejar de predicar ni de mantener una "una fluida relación con el Espíritu Santo quien es nuestro ayudador". Concluían con un mensaje esperanzador para las iglesias: "recordemos que los tiempos donde más creció la Iglesia fueron los días en que estuvo bajo el fuego de la prueba. La iglesia crecerá y no nos detendremos hasta que Argentina sea para Cristo". ${ }^{21}$ Según el mensaje de los obispos de la diócesis de Quilmes: "Hizo falta que llegue una noche oscura, como la pandemia, para que se encendiera en el corazón una luz que muestra cosas que no veía. Fue necesario morir a lo que era lo común de siempre, para que nazca algo nuevo. ${ }^{22} \mathrm{Algu}-$ nos días después el obispo de Catamarca, monseñor Urbanc, fue más explícito en este discurso al sostener que lo que estaba viviendo la humanidad reflejaba "la prepotencia de los poderosos y de los gobernantes, que creen que el mundo está en sus manos, y que incluso Dios tiene que someterse a sus planes". ${ }^{23}$ En cierto modo, la pandemia -al menos para estos especialistas religiosos- parecía estar creando las condiciones para una relocalización de lo religioso en el marco de una "sociedad estructuralmente impotente" para proveer de las "esperanzas" necesarias para "seguir existiendo" (Hervieu-Léger, 2004, pp. 122-123).

Por lo pronto, de todas maneras, esta lectura del sentido de la pandemia no derivó en un cuestionamiento a las medidas tomadas en el ámbito sanitario. En la "nueva cotidianidad" se perfilaba una delimitación de los espacios de acción según la cual, mientras la medicina debía encontrar la vacuna para ponerle fin a la amenaza del virus, a la religión le correspondía acompañar a un ser humano en crisis, que ante la adversidad redescubría su fragilidad esencial. El presbítero responsable del servicio religioso de un hospital expli-

\footnotetext{
${ }^{19}$ Barone, C. (2020, abril). Contratacar al virus.Familia Cristiana. Recuperado de http://www.familiacristiana.org. ar/archivo/imagenes/2020/abril2020.doc.

${ }^{20}$ De las Heras Muela, J. (2020, abril). Esta es la pascua.Familia Cristiana. Recuperado de http://www.familiacristiana.org.ar/archivo/imagenes/2020/abril2020.doc

${ }^{21}$ Nueva carta a la pastoral de Argentina ante la pandemia (2020, 12 de mayo). Recuperado de https://www.aciera.org/nueva-carta-a-la-pastoral-de-argentina-ante-la-pandemia/.

${ }^{22}$ En Pascua, los obispos llaman a vivir con esperanza este tiempo de oscuridad (2020, 14 de abril). BO-AICA. Recuperado dehttps://www.aica.org/noticia-en-pascua-los-obispos-llaman-a-vivir-con-esperanza-este-tiempo-de-oscuridad.

${ }^{23}$ Septenario en honor de la Virgen del Valle: Homenaje al personal sanitario (2020, 21 de abril). BO-AICA. Recuperado de https://www.aica.org/noticia-septenario-en-honor-de-la-virgen-del-valle-homenaje-al-personal-sanitario.
} 
caba que lo que intentaba comunicar a los pacientes era "que Dios los acompañaba" que el "nuestro era un Dios cercano, que Jesús estaba atento a todos, pero especialmente a los que sufrían, y que acompañaba esa cruz, ese momento difícil”. ${ }^{24}$ En palabras del cardenal Mario Poli, arzobispo de Buenos Aires, la religión estaba para dar "fuerza, paz y consuelo" y para demostrar que "Dios nos acompaña." ${ }^{25}$ Desde ACIERA se recalcaba de igual manera la importancia del acompañamiento, en especial del personal médico. Con el lema "Juntos en tiempos de pandemia" se organizaron diferentes encuentros virtuales sobre el valor de lo espiritual para enfrentar la adversidad y en especial para concientizar sobre la importancia de "cuidar a quienes nos cuidan". ${ }^{26}$

Por supuesto, no faltaron también las oraciones tanto de católicos como de evangélicos por el fin de la pandemia. Si bien no fueron lo más habitual al comienzo, su frecuencia fue en aumento con el correr de los meses. En Tartagal, provincia de Salta, por ejemplo, evangélicos y católicos se unieron en rezo y lo mismo ocurrió en otras ciudades en el marco de una iniciativa de la Conferencia Episcopal Argentina (CEA) y ACIERA. ${ }^{27}$ También se multiplicaron las cadenas de oración en diferentes puntos del país, en especial durante la Pascua. Por ejemplo, el obispo de Posadas, Juan Rubén Martínez, anunció que en Semana Santa rezarían "a Jesucristo para que esta pandemia termine, encomendándonos a la protección de María, nuestra madre". ${ }^{28}$ De igual manera, el vicario general de Paraná aprovechó el aniversario de la elevación a Villa de la Baxada de Paraná, para pedir a la Virgen protección y amparo. ${ }^{29}$

No obstante, el auge de las plegarias no supuso, al menos en el discurso, un reencantamiento del mundo. En ningún momento se atribuyó a Dios el advenimiento de la pandemia en clave de castigo -o de un mensaje a descifrar- y si bien se iniciaron cadenas de oración para que terminara, salvo casos puntuales, no se pidió directamente su intervención en la historia humana. En el caso del vicario general de Paraná, ante la confusión generada por el pedido de intervención a la Virgen, fue el propio arzobispo el que aclaró públicamente que si bien el vicario había recordado el pasado milagroso de la Virgen lo que se buscaba ahora con la invocación era simplemente la "ayuda de la Virgen para los creyentes y no creyentes" para "sobrellevar esta prueba impensada" ${ }^{30}$ Es cierto que en los documentos de ACIERA sobre pastoral se apeló con mayor frecuencia al Espíritu San-

\footnotetext{
24 "Cristo presente en el enfermo": El acompañamiento espiritual en los hospitales (2020, 1 de abril). BO-AI$C A$. Recuperado de https://www.aica.org/noticia-cristo-presente-en-el-enfermo-el-acompanamiento-espiritual-en-los-hospitales.

${ }^{25}$ El Card. Poli dio inicio a la Semana Santa: "Jesús está pensando en nosotros" (2020, 6 de abril). BO-AICA. Recuperado dehttps://www.aica.org/noticia-el-card-poli-dio-inicio-a-la-semana-santa-jesus-esta-pensando-ennosotros.

${ }^{26}$ Juntos en tiempo de pandemia (2020, 24 de julio). Recuperado de https://www.aciera.org/juntos-en-tiempo-de-pandemia/

${ }^{27}$ Cristianos de Tartagal harán una oración para pedir el fin de la pandemia (2020, 9 de abril). BO-AICA. Recuperado de https://www.aica.org/noticia-cristianos-de-tartagal-haran-una-oracion-para-pedir-el-fin-de-la-pandemia.

${ }^{28}$ El obispo de Posadas incluye en los sufrimientos de Cristo el flagelo de la pandemia (2020, 8 de abril). BO-AI$C A$. Recuperado de https://www.aica.org/noticia-el-obispo-de-posadas-incluye-en-los-sufrimientos-de-cristo-elflagelo-de-la-pandemia.

${ }^{29}$ El arzobispado de Paraná aclaró cuál fue la intención del cura. Recuperado de https://www.valoresreligiosos. com.ar/Noticias/el-arzobispado-de-parana-aclaro-cual-fue-la-intencion-del-cura-17970

${ }^{30}$ El arzobispado de Paraná aclaró cuál fue la intención del cura. Recuperado de https://www.valoresreligiosos. com.ar/Noticias/el-arzobispado-de-parana-aclaro-cual-fue-la-intencion-del-cura-17970.
} 
to, en el marco de una concepción teológica que concibe lo milagroso como una realidad más cotidiana y menos excepcionalista, pero aún en estos documentos no se dejó de proponer una relación de complementariedad con el saber biomédico. En este sentido, son muy interesantes los pedidos de cumplimiento de los protocolos sanitarios que, por esos días, ACIERA hizo llegar a las iglesias y la confección incluso de un manual, enviado frente a la eventual apertura de algunos templos en determinadas ciudades y localidades. En el manual, lejos de centrarse en la realización de cadenas de oración o plegarias, se recopilaban diferentes recomendaciones de los expertos médicos nacionales y se pedía a los pastores ser muy prudentes y trabajar siempre "mancomunadamente con los gobiernos locales" a fin de establecer los pasos a seguir en cada caso. En ese sentido, dichos documentos e intervenciones, dejaban en claro que la confianza en Jesús y el Espíritu Santo de ninguna manera debían derivar o traducirse en una minusvaloración del criterio médico y sanitario para enfrentar la pandemia. También dejaban entrever una concepción teológica ciertamente desencantada si miramos las cosas en el largo plazo, muy alejada de aquella que habían dado por supuesto, por ejemplo, los difusores de la fakenews con la que iniciamos el artículo. Una perspectiva, de hecho, muy en sintonía con la reflexión del teólogo católico Ariel Álvarez, para quien desde que Dios creó el mundo:

dejó a los hombres como sus representantes para colaborar, servir y actuar en su nombre [...] Sin una persona que se ofrezca a colaborar, Dios no puede actuar. Es triste ver cómo seguimos pidiéndole a Dios que haga cosas, en lugar de ofrecernos nosotros a hacer algo. Seguimos creyendo que él puede introducirse desde afuera y manipular la creación, cuando en realidad él está esperando que nosotros nos decidamos a actuar [...] Los cristianos tenemos una manera infantil de orar. Siempre estamos pidiendo a Dios que solucione los problemas y arregle los conflictos que, en realidad, nosotros provocamos. Pero esa no es la misión de Dios. Su tarea es la de darnos la fuerza, el valor, la inteligencia, la voluntad, la capacidad para que nosotros los solucionemos. ${ }^{31}$

En la misma tónica, la cadena de oración lanzada por ACIERA a finales de julio no ponía el eje en que Dios interviniera para detener la pandemia sino para que "concediera sabiduría a las autoridades en cada lugar" y "fortaleciera a los creyentes" para convertirlos en "factores de bendición en sus comunidades". 32

Dicha concepción teológica se expresó también en la intensión de lograr una rápida adaptación de las prácticas litúrgicas y demás actividades de las iglesias a las condiciones que fijaba el ASPO. Inicialmente, al menos, ni la Agencia Informativa Católica ni los boletines de ACIERA o los comunicados de FAIE registraron quejas, reacciones encontradas o voces disonantes ante las restricciones. La modificación de las prácticas, en particular su reconversión en el formato de las "nuevas tecnologías", se fue consolidando a medida que se extendían las restricciones durante el mes de abril. Desde la CEA y a través del Secretariado Nacional de Liturgia se dio a conocer una guía para la celebración de la pascua y lo mismo plantearon las asociaciones de iglesias evangélicas. ${ }^{33}$ Las recomendaciones

\footnotetext{
${ }^{31}$ Álvarez Valdés, A. La pandemia renueva el interrogante: ¿Por qué Dios permite las catástrofes? Clarín. Recuperado de https://www.clarin.com/sociedad/-dios-permite-catastrofes-_0_R5cnxm3-g.html.

${ }^{32}$ ACIERA promueve la oración (2020, 24 de julio). Recuperado de https://www.aciera.org/aciera-promueve-la-oracion/

${ }^{33}$ Secretariado Nacional de Liturgia, Celebración familiar para el Domingo de Ramos en la Pasión del Señor. Recuperado dehttps://episcopado.org/docs/2394/Domingo-de-Ramos.-05042020.pdf.
} 
expresaban la flexibilización de la práctica litúrgica en adaptación al contexto, lo que se trasladó a otras celebraciones litúrgicas, encuentros, retiros y charlas. ${ }^{34}$ Monseñor García, obispo de San Justo invitó a vivir la "\#SemanaSantaEnCasa” y, con el lenguaje de las redes sociales, adelantó: “También te vamos a tirar algunos 'tips' para que puedas hacerlo en familia y unirte más a este Jesús que pasa por nuestra vida dejando su salvación. Animate, seguimos". ${ }^{35}$ La reconversión de las actividades se multiplicó: vía crucis por Instagram, ${ }^{36}$ "miércoles crismal virtual" en Paraná ${ }^{37}$, "la bajada" de la imagen de la Virgen del Valle en Catamarca a través de los medios audiovisuales, ${ }^{38}$ videomensajes en varias diócesis, recorridas de la Virgen de Lujan en helicóptero ${ }^{39}$, "rosario virtual de bendiciones" ${ }^{40}$ Un cóctel de opciones que no dejaría de crecer en los meses siguientes.

\section{De la aparición de voces críticas a la amenaza de la "grieta"}

Durante los primeros meses de avance del virus, en paralelo con las declaraciones de apoyo al ASPO, los principales referentes evangélicos y de la Iglesia católica fueron hilvanando una lectura más general sobre la pandemia que ensayaba una crítica profunda a las versiones antirreligiosas de la modernidad -y ciertas dimensiones de la modernidad misma-, al tiempo en que alentaba una revalorización de lo espiritual. Aunque esta perspectiva no implicó necesariamente un reposicionamiento de lo religioso en términos inte-

\footnotetext{
${ }^{34}$ La guía incluía las pautas pormenorizadas de la celebración tanto en la disposición de los elementos, "signos" que permitirían expresar la fe, hasta las palabras y roles que deberían interpretar los miembros de la familia. Luego, se dieron indicaciones para la celebración del "Triduo Pascual” del mismo tenor, con indicaciones precisas para el jueves, viernes y domingo. CEA (2020, 6 de abril). Triduo Pascual 2020: Celebraciones para los hogares. Recuperado de https://episcopado.org/contenidos.php?id=2402\&tipo=unica.

${ }^{35}$ Mons. García invita a sumarse "en comunión especial" a la \#SemanaSantaEnCasa (2020, 2 de abril). BO-AICA. Recuperado de https://www.aica.org/noticia-mons-garcia-invita-a-sumarse-en-comunion-especial-a-la-semanasantaencasa.

${ }^{36}$ Crónica Blanca hará su tradicional viacrucis por Instagram (2020, 9 de abril). BO-AICA. Recuperado dehttps:// www.aica.org/noticia-cronica-blanca-hara-su-tradicional-viacrucis-por-instagram.

${ }^{37}$ El clero de Paraná tuvo un "miércoles crismal virtual" (2020, 9 de abril). BO-AICA. Recuperado de https:// www.aica.org/noticia-el-clero-de-parana-tuvo-un-miercoles-crismal-virtual.

${ }^{38} \mathrm{La}$ "bajada" de la imagen de la Virgen del Valle se vivió desde los hogares (2020, 19 de abril). BO-AICA. Recuperado de https://www.aica.org/noticia-la-bajada-de-la-imagen-de-la-virgen-del-valle-se-vivio-desde-los-hogares. ${ }^{39}$ Pandemia: La Virgen de Lujan en helicóptero para bendecir a los argentinos (2020, 20 de abril). BO-AICA. Recuperado de https://www.aica.org/noticia-pandemia-la-virgen-de-lujan-en-helicoptero-para-bendecir-a-los-argentinos.

${ }^{40} \mathrm{Gran}$ rosario virtual de bendiciones para la familia (2020, 23 de abril). BO-AICA. Recuperado de https:// www.aica.org/noticia-gran-rosario-virtual-de-bendiciones-para-la-familia. Para algunos el paso a lo virtual tenía sus complicaciones. En una nota de AICA los sacerdotes de Paraná relataban los problemas "técnicos" que habían debido superar para lograr comunicarse durante la cuarentena. El clero de Paraná tuvo un "miércoles crismal virtual (2020, 9 de abril). BO-AICA. Recuperado dehttps://www.aica.org/noticia-el-clero-de-parana-tuvo-un-miercoles-crismal-virtual. Para otros, en cambio, fue la posibilidad de consolidar y expandir experiencias previas, como el caso del sacerdote tucumano Luis Zazano quien, a raíz del aparente éxito de los audios que solía enviar por WhatsApp, fundó la comunidad Misioneros Digitales Católicos y frente a la situación creada por la pandemia entendía que "va a existir un antes y un después, porque lo digital nos ha salvado la cercanía como Iglesia, y en ese sentido ha marcado muchísimo: el Papa con su salud, con la bendición Urbi et Orbi y todos los recursos digitales que se están utilizando están marcando mucho. Creo que la Iglesia formará una comisión o algún espacio para trabajar la misión digital, pero algo se fortalecerá en relación a todo esto". Luis Zazano: "Lo digital ha salvado la cercanía de la Iglesia" (2020, 21 de abril). BO-AICA. Recuperado de https://www.aica.org/ noticia-p-luis-zazano-lo-digital-ha-salvado-la-cercania-de-la-iglesia.
} 
gralistas o totalizadores, sí generó las condiciones para la emergencia de otros discursos, algunos de ellos, más combativos. En Argentina, además, la polarización política moderada brevemente por el inicio de la pandemia, volvió con fuerza en el mes de mayo, resignificando en sus propios términos las intervenciones religiosas.

Durante mayo y junio, comenzaron a ganar espacio y visibilidad voces críticas que se manifestaban contra una supuesta falta de consideración de las necesidades espirituales de la población. Desde el programa televisivo Claves para un mundo mejor el obispo auxiliar de La Plata y presidente de la Comisión Episcopal de Pastoral de la Salud, Alberto Bochatey, en el comienzo claramente a favor del ASPO, sostuvo ahora, sin embargo, que mientras todo el tiempo se habla del virus, de la cantidad de infectados y de muertos se deja "muy poco espacio a las necesidades espirituales que tiene un enfermo o alguien que está sano pero con la angustia de poder infectarse."41 De igual manera, para el arzobispo de San Juan, no había que dejar de lado el acompañamiento religioso ni olvidar lo espiritual, ${ }^{42}$ reclamo en el que coincidía con el arzobispo emérito de La Plata, Héctor Aguer, quien se mostró particularmente contrariado por las escasas invocaciones a Dios por parte del gobierno argentino. Tensando la cuerda, las contrapuso a las del presidente de los EEUU, Donald Trump, quien, según Aguer, había dicho "cosas preciosas insistiendo en que es necesario pedir ayuda a Dios para que nos libre de este contagio" y para que "podamos salir indemnes de esta pandemia". En su opinión, la clave pasaba por "rezar mucho más en este tiempo" y, de hecho, por esos días, se multiplicaron las iniciativas impulsadas desde las autoridades de la Iglesia católica. La CEA convocó al resto de las comunidades religiosas del país a realizar una oración por la humanidad ${ }^{43}$ y crecieron significativamente los pedidos a la Virgen de Lujan o a la de Itatí para superar la pandemia. ${ }^{44}$

Las críticas de Aguer iban también más allá de lo religioso y se centraban en los decretos del Poder Ejecutivo que, en su opinión, alejaban al país de la "normalidad republicana y democrática”, en sintonía con los reclamos de algunos sectores de la oposición política que venían ganando fuerza. ${ }^{45}$ Más crítica aún, la Corporación de Abogados Católicos consideró que se estaba gobernando al margen del "ordenamiento legal" y evaluaron que tras el propósito de preservar vidas se restringían inadmisiblemente "libertades, derechos y garantías fundamentales de las personas reconocidos en la Constitución Nacional”. Según la Corporación, las restricciones impuestas afectaban gravemente a la Iglesia "por la prohibición de la concurrencia de personas a la celebración de la Santa Misa y la administración habitual de los sacramentos" ${ }^{46}$

\footnotetext{
${ }^{41}$ Defender la vida contra el virus, pero también contra el aborto (2020, 7 de mayo). BO-AICA. Recuperado de https://www.aica.org/noticia-defender-la-vida-contra-el-virus-pero-tambien-contra-el-aborto.

${ }^{42}$ Mons. Lozano: Respuestas humanas y espirituales para afianzar la esperanza (2020, 10 de mayo). BO-AICA. Recuperado de https://www.aica.org/noticia-mons-lozano-respuestas-humanas-y-espirituales-para-afianzar-la-esperanza

${ }^{43}$ En comunión con el Papa, la CEA invita a rezar por la Humanidad (2020, 5 de mayo). BO-AICA. Recuperado de https://www.aica.org/noticia-en-comunion-con-el-papa-la-cea-invita-a-rezar-por-la-humanidad.

${ }^{44}$ Mons. Canecín: "A la Virgen recurrimos confiados en este tiempo de prueba" (2020, 7 de mayo). BO-AICA. Recuperado de https://www.aica.org/noticia-mons-canecin-a-la-virgen-recurrimos-confiados-en-este-tiempo-de-prueba.

${ }^{45}$ Mons. Héctor Aguer: Apostillas religiosas en cuarentena (2020, 18 de junio). BO-AICA. Recuperado de https:// www.aica.org/noticia-mons-hector-aguer-apostillas-religiosas-en-cuarentena.

${ }^{46}$ Declaración de los abogados católicos a 100 días del aislamiento (2020, 27 de junio). BO-AICA. Recuperado de https://www.aica.org/noticiaabogados-catolicos-piden-evaluar-el-retorno-gradual-de-las-misas-con-fieles.
} 
En un clima más tenso, a mediados de julio, el cardenal Mario Poli, arzobispo de Buenos Aires, firmó una declaración junto al gran rabino Gabriel Davidovich, monseñor Pablo Hakimian, patriarca de los Armenios, y monseñor Iosif Bosch, arzobispo de la Iglesia ortodoxa griega de Buenos Aires y Sudamérica, a través de la cual le reclamaba al Jefe de Gobierno de la ciudad de Buenos Aires, Horacio Rodríguez Larreta -y al poder político en general-, mayor consideración hacia las prácticas religiosas a la hora de establecer las medidas sanitarias y los permisos para distintos rubros de actividad. ${ }^{47}$ La declaración comenzaba señalando que si bien la encuesta sobre creencias realizada por investigadores del CONICET, ponía de manifiesto que el 80\% de los argentinos tenía una adscripción religiosa, las costumbres espirituales no aparecían como prioritarias en las normativas sanitarias emitidas. Sin rodeos, los representantes religiosos hablaron de que se "intentaba invisibilizar a Dios" corriéndolo de la escena "como si la superación de lo que nos desafía estuviera en manos de un Estado omnipotente". Luego ofrecieron una de las menciones más explicitas al lugar que se le debía asignar a la religión en el escenario pandémico al sostener:

No olvidemos que el resultado siempre está en manos de Dios. El mismo Dios que ordena ir al médico es el Dios que cura. Hay que utilizar las mayores inteligencias para investigar en la ciencia, analizar todos los datos, y plantear las mejores soluciones; pero seguro que no menos energía hay que dedicar a implorar a Dios para que nos asista con su misericordia y ponga fin a esta pandemia. ${ }^{48}$

El reclamo -que poco después obtuvo respuesta favorable de parte del gobierno de la ciudad Buenos Aires- fue respaldado por los obispos de la arquidiócesis. Alejandro Giorgi, obispo auxiliar, sostuvo "vivimos un momento inédito en la historia universal y esta pandemia nos agarró a todos desprevenidos, por ello también experimentamos incertidumbre y, pasados los primeros meses de la cuarentena, Dios no aparecía. Teníamos infinidad de recaudos sanitarios, la preocupación por la pobreza creciente, las empresas y comercios que cerraban ... y Dios no estaba”. En la misma línea, aunque con un tono más combativo, el obispo de Concordia, en la provincia de Entre Ríos, monseñor Collazuol señalaba que:

el ejercicio del derecho de expresar y celebrar públicamente la propia creencia no es una gracia o concesión de la autoridad, cualquiera sea. Es un derecho natural y universal (...) El ejercicio de este derecho puede ser reglamentado por el Estado sin más limitaciones que las impuestas por la moral, las buenas costumbres y el orden público. Sin embargo, las disposiciones gubernamentales en tal sentido no constituyen al fiel ni a la comunidad creyente en sujetos 'hábiles' para la actividad religiosa, ni ésta se hace posible de practicar por una concesión de la 'autoridad' civil (...) En este sentido, la flexibilización de las restricciones a la práctica, el culto y la observancia de las propias creencias, no es una gracia concedida por el Estado a las Iglesias sino un viabilizar en nuevas circunstancias el ejercicio de un derecho propio. ${ }^{49}$

\footnotetext{
${ }^{47}$ Coronavirus en Argentina: representantes de entidades religiosas reclamaron la apertura de los templos en la ciudad de Buenos Aires (2020, 15 de julio). Infobae. Recuperado de https://www.infobae.com/coronavirus/2020/07/15/coronavirus-en-argentina-representantes-de-entidades-religiosas-reclamaron-la-apertura-de-los-templos-en-la-ciudad-de-buenos-aires/.

${ }^{48}$ La práctica religiosa "no es una actividad esencial, es una necesidad vital" (2020, 15 de julio). BO-AICA. Recuperado de https://www.aica.org/noticia-la-practica-religiosa-no-es-una-actividad-esencial-es-una-necesidad-vital. ${ }^{49}$ Mons. Collazuol: “'Habilitar’ o 'autorizar’ actividades religiosas?” (2020, 15 de julio). BO-AICA. Recuperado de https://www.aica.org/noticia-mons-collazuol-habilitar-o-autorizar-actividades-religiosas.
} 
El presidente del Consejo Argentino para la Libertad Religiosa (CALIR), Raúl Scialabba, consideraba que el ASPO había afectado la libertad religiosa porque, argumentaba, las restricciones "deben ser establecidas por ley -cosa que no sucedió- por un tiempo determinado y ser de carácter razonable y sin discriminaciones" y en este sentido señalaba que "desde el primer minuto de la cuarentena se ignoró la dimensión integral del hombre" lo que quedaba en evidencia en el hecho de que los "religiosos no fueron considerados personal esencial y tampoco la asistencia que prestan”. Scialabba concluía que, aparentemente, "las iglesias y confesiones religiosas" eran "tomadas como muy importantes a la hora de la asistencia solidaria (y realmente lo son), pero ignoradas en la función de asistencia espiritual". ${ }^{50}$ Para Juan Navarro Floria, docente en la Universidad Católica Argentina, la libertad religiosa se había afectado porque "no se cumplió la formalidad de la ley y las restricciones" eran "irrazonables por su extensión y su duración”. En su opinión se había restringido "indebidamente el derecho a recibir asistencia religiosa (especialmente a los enfermos y moribundos) y la posibilidad de despedir adecuadamente a los difuntos" como consecuencia de "un desborde autoritario del Estado" y porque -en lo que constituía una crítica a las jerarquías católicas- "las confesiones religiosas fueron extremadamente cautelosas y no quisieron hacer planteos". ${ }^{1}$

El clima de malestar se hizo sentir también por abajo -entre pastores y curas- y se tradujo en algunas acciones concretas de protesta, por lo general a posteriori desacreditadas y cuestionadas por las autoridades religiosas. En la provincia de Santa Fe, por ejemplo, un templo evangélico de la ciudad de San Lorenzo realizó una auto-misa con 250 vehículos presentes y puso en marcha, incluso, lo que denominó un "culto-bar" para setenta personas, con el propósito de cuestionar el lugar que las autoridades locales daban a lo religioso, puesto que se había autorizado la apertura de los bares pero no de los templos. ${ }^{52}$ En Orán, Salta, a pesar de encontrarse en fase 1 por el creciente número de contagios, ${ }^{53} \mathrm{el}$ obispo local sacó en caravana al santo patrono, con apoyo de la Gendarmería y la Policía, generando aglomeraciones de fieles y la reacción de las autoridades municipales y de la justicia federal. Ante las críticas, lejos de retroceder, el obispo consideró que la caravana se había realizado en perfecto orden y que la gente simplemente había salido de sus casas a saludar, muy lejos de las 'aglomeraciones' que se permitían en bancos y ferias". ${ }^{4}$

Sin embargo, más allá de estos casos, si se mira el panorama completo, las señales de malestar no derivaron en un cuestionamiento general al ASPO o al criterio biomédico. Tampoco dieron paso a una oleada de protestas y desobediencias masiva. Casos como los

\footnotetext{
${ }^{50}$ Restricciones por el coronavirus: ¿La cuarentena cercenó la libertad religiosa? (2020, 12 de agosto). Clarín. Recuperado de https://www.clarin.com/sociedad/-cuarentena-cerceno-libertad-religiosa-_0_DQ7IXravM.html.

${ }^{51}$ Restricciones por el coronavirus: ¿La cuarentena cercenó la libertad religiosa? (2020, 12 de agosto). Clarín. Recuperado de https://www.clarin.com/sociedad/-cuarentena-cerceno-libertad-religiosa-_0_DQ7IXravM.html.

${ }^{52}$ Santa Fe: una iglesia evangélica hizo una auto-misa sin autorización y participaron unas 250 familias (2020, 16 de junio). El Litoral. Recuperado de https://www.ellitoral.com/index.php/id_um/244690-santa-fe-una-iglesia-evangelica-hizo-una-automisa-sin-autorizacion-y-participaron-unas-250-familias--duro-una-hora-que-es-eltiempo-que-se-permite-para-la-recreacion-dijo-la-pastora-de-la-iglesia-regi\#: :text=Una\%20iglesia\%20evang\%C3\%A9lica\%20realiz\%C3\%B3\%20una,\%22Fue\%20todo\%20ordenado.

${ }^{53}$ En el ASPO la Fase 1 era la de máximas restricciones, cuando solo se permitía la circulación de aquellas personas afectadas a las tareas esenciales.

${ }^{54}$ Denunciaron al Obispado de Orán por incumplir las medidas sanitarias (2020, 1 de septiembre). Página 12. Recuperado de https://www.pagina12.com.ar/288990-denunciaron-al-obispado-de-oran-por-incumplir-las-medidas-sa
} 
de Orán o San Lorenzo no dejaron de ser excepciones. De igual manera, los exabruptos de Aguer o las críticas de la Corporación de Abogados Católicos, no lograron mayor eco entre las autoridades religiosas que, por el contrario, buscaron poner paños fríos y evitar cualquier forma de confrontación. Desde la Iglesia Evangélica del Río de La Plata (IERP), por ejemplo, la pastora Sonia Skupch tomaba distancia de las críticas y de las acciones de rebeldía de algunos pastores puesto que, en su opinión, "las restricciones propias de la cuarentena buscaban preservar la salud de la población en general y en especial de los más vulnerables", a quienes precisamente como cristianos estaban "llamados a cuidar". Por si quedaban dudas, concluía afirmando que se trataba de "medidas de emergencia y como tales debían ser entendidas", sin hacer especulaciones fuera de lugar. ${ }^{55}$ Muy similar era la mirada del obispo católico Enrique Eguía Seguí, quien consideraba que "el anuncio del Evangelio y la celebración del culto" se había podido mantener "a través de renovadas y creativas formas en las redes sociales", llegando incluso "a gente que no se acerca habitualmente a los templos, aunque se reconozca católica”. No negaba que la celebración de los sacramentos de "manera comunitaria y presencial en los templos" se hubiera afectado, pero había sido en "función de privilegiar un valor que es el de cuidar la vida de los demás y la propia, evitando el contagio". En franca oposición a Floria, considerada que la "libertad de anunciar a Cristo y servir a los hermanos" no había tenido "limitaciones". 56 En ese sentido, las palabras de Seguí y de otros miembros de la jerarquía católica y del clero eran también una respuesta directa a la campaña internacional "Devuélvannos la misa”, que había tenido un cierto eco en algunos sectores católicos opuestos al gobierno a nivel local. Las contestaciones más duras provinieron en esta oportunidad de los Curas en Opción por los Pobres y de aquellos que, sin tener participación orgánica en el grupo, desarrollaban tareas pastorales entre las clases populares. Lejos de la moderación de las autoridades nacionales, respondieron con dureza, apelando a tópicos y argumentos de la llamada "teología del pueblo", con algunos aditamentos de la teología de la liberación. En una prueba más de que el catolicismo argentino no escapaba a las tensiones que se registraban en la sociedad local ni había dejado totalmente en el pasado las líneas de fractura de los años sesenta y setenta. El obispo Eduardo García, de la diócesis de San Justo, consideró totalmente inapropiado el reclamo porque "pareciera que la suspensión de actividades, dentro de las que se encuentra el culto, no por el culto en sí mismo sino por la congregación de gente y la posibilidad de contagio, fuera una cuestión arbitraria. Cuando no lo es”. Además, agregó:

Si viviéramos realmente como pueblo deberíamos escuchar también 'devuélvannos la educación, devuélvannos Cáritas, devuélvannos el trabajo, devuélvannos la salud', devuélvannos tantas cosas que resignamos en esta cuarentena atendiendo al bien mayor que es la salud de toda la población. ${ }^{57}$

Según García, lo que definía a un cristiano "no era el ser virtuoso u observante, sino el vivir confiando en un Dios cercano por el que se siente amado sin condiciones (...)

\footnotetext{
${ }^{55}$ Libertad religiosa: Los clérigos y los juristas fijan su posición (2020). Valores Religiosos. Recuperado de https:// www.valoresreligiosos.com.ar/Noticias/libertad-religiosa-los-clerigos-y-los-juristas-fijan-su-posicion-18272.

${ }^{56}$ Libertad religiosa: Los clérigos y los juristas fijan su posición (2020). Valores Religiosos. Recuperado de https:// www.valoresreligiosos.com.ar/Noticias/libertad-religiosa-los-clerigos-y-los-juristas-fijan-su-posicion-18272.

${ }^{57}$ Un obispo dice que la prioridad hoy es la ayuda social, no la misa (2020). Valores Religiosos.https://www.valoresreligiosos.com.ar/Noticias/un-obispo-dice-que-la-prioridad-hoy-es-la-ayuda-social-no-la-misa-17502.
} 
Con esta certeza, hoy más que nunca, la Iglesia y los cristianos" tenían "que dar el testimonio de entrega generosa por amor al que más sufre, creando ambientes de calma, servicio y esperanza. En este tiempo más que nunca" se aplicaban las palabras del papa Francisco: "la iglesia como hospital de campaña". Agregaba, asimismo, que si bien como "pastor y hombre que amaba la Eucaristía" la celebraba todos los días a través de las redes sociales "para acompañar el camino de la fe" consideraba que claramente eran otras las prioridades "para poder vivir la fe en serio, en lo esencial".

Adorar el cuerpo de Cristo y no comprometerse eficazmente con la vida del hermano no es cristiano. (...) Con asombro leí, y lo respeto, la angustia que en muchos provocaba no poder comulgar, acaso experimentan la misma angustia al no poder salir a ayudar en una salita de primeros auxilios o a un anciano que está aislado. También escuché que sienten que la fe se les debilita al no poder comulgar y me pregunto: los mártires encarcelados del siglo pasado y de este siglo que no podían acceder a la misa en sus cautiverios y dieron su vida, ¿cómo lo hicieron? (...)

Creo firmemente en el Señor presente en la Eucaristía, centro y culmen de la vida cristiana, pero desde una comunidad que celebra y toma la fuerza para vivir jugándose por la vida de los demás, no como un selfservice de la gracia o un Redoxon de la vida espiritual. De muy poco servirá la reapertura gradual de los templos si no hay una reapertura radical de la Iglesia de cara a la realidad, sin ombliguismos seudo religiosos de autocomplacencia. ${ }^{58}$

\section{Reflexiones finales}

El caso del arzobispado de Paraná al que nos referimos en el artículo refleja muy bien el nivel de desencantamiento del discurso religioso frente a la pandemia. Ante las dudas generadas por la invocación del vicario general de la diócesis a la Virgen, fue el propio arzobispo el que salió a explicar públicamente que lo que se había buscado no era, como antaño, que Dios interviniera para poner fin al virus, sino acompañamiento y fortaleza espiritual para creyentes y no creyentes. De igual manera, las cadenas de oración impulsadas por las asociaciones de iglesias evangélicas pidieron al Espíritu Santo fuerzas y contención espiritual, más que su acción concreta en la historia humana. Por supuesto, la posibilidad del milagro está presente en cada intervención -más claramente en el caso de algunos de los comunicados de ACIERA- pero no ha sido la hipótesis principal de las instituciones religiosas a la hora de planificar sus acciones concretas ni el argumento principal de sus discursos. Al menos, claro está, en una mirada desde arriba, centrada en las autoridades del mundo cristiano argentino.

Por otro lado, la secularización del discurso religioso se ha manifestado también en la naturalización de una clara diferenciación de planos y dimensiones en la vida social. En todos los casos se aceptó la centralidad del saber biomédico para enfrentar la pandemia y se reconoció también la autonomía de la esfera política para actuar en consecuencia. El reclamo de una mayor atención a lo religioso, por tanto, no debería interpretarse -al menos por el momento- como un indicio neointegralista, más allá de algunas voces aisladas. Por el contrario, las declaraciones que hemos recuperado en este artículo afirman la importancia de lo espiritual pero no como un principio jerárquico de orden social sino

\footnotetext{
${ }^{58}$ Un obispo dice que la prioridad hoy es la ayuda social, no la misa (2020). Valores Religiosos. https://www.valoresreligiosos.com.ar/Noticias/un-obispo-dice-que-la-prioridad-hoy-es-la-ayuda-social-no-la-misa-17502.
} 
como un aspecto en serie con otros de la vida humana. En esta clave, se ha promovido la difusión de una antropología humana más integral -no integralista- que incorpora lo religioso como una dimensión esencial y constitutiva y, por tanto, como un aspecto ineludible a la hora de planificar las políticas públicas y las acciones de gobierno. En concreto, en el marco de la ASPO, esto supondría comenzar a considerar a las prácticas religiosas dentro de las actividades esenciales permitidas e implicaría, asimismo, el apoyo estatal para su concreción en complementariedad con la atención médica.

La evolución de la pandemia -y en el caso argentino la profundización o no de la polarización política- dirán si estas tendencias se mantienen estables en el tiempo o, por el contrario, dan paso a nuevas formas de reencantamiento del mundo, a la profundización de los conflictos entre las diferentes tendencias teológicas del mundo cristiano y/o al surgimiento de expresiones neointegralistas más o menos combativas.

\section{Bibliografía}

Di Stefano, R. y Zanatta, L. (2000). Historia de la Iglesia Argentina. Desde la Conquista hasta fines del siglo XX. Buenos Aires, Argentina: Mondadori.

Di Stefano, R. y Zanca, J. (2013). Pasiones anticlericales. Un recorrido iberoamericano. Bernal, Argentina: UNQUI.

Frigerio, A. (2020). Seminario sobre Reacciones Religiosas al Covid-19 en América Latina (mesa 2). Diversa. Red de Estudios de la Diversidad Religiosa en Argentina. Recuperado de http://www.diversidadreligiosa.com.ar/blog/seminario-sobre-reacciones-religiosas-al-covid-19-en-america-latina-mesa-2/?fbclid=IwAR0e9sPn-imHYwPx1iqX1DtZf9pM75EW8jkVVdf3Zxg4bOVxVf3FjJ_hpEM

Ghio, J. M. (2007), La iglesia católica en la política argentina. Buenos Aires, Argentina: Prometeo.

Hervieu-Léger, D. (2004). El peregrino y el convertido. La religión en movimiento. México: Ediciones del Helénico.

Lida, M. (2015). Historia del catolicismo en la Argentina. Entre el siglo XIX y el XX, Buenos Aires, Argentina: Siglo XXI.

Viotti, N. (2020). Creencia y negacionismo científico en tiempos de COVID 19. Diversa. Red de Estudios de la Diversidad Religiosa en Argentina. Recuperado dehttp:// www.diversidadreligiosa.com.ar/blog/creencia-y-negacionismo-cientifico-en-tiempos-de-covid-19/. 